\title{
The LACOG-0415 phase II trial: abiraterone acetate and ADT versus apalutamide versus abiraterone acetate and apalutamide in patients with advanced prostate cancer with non-castration testosterone levels
}

Gustavo Werutsky ${ }^{1 *}$, Fernando Cotait Maluf ${ }^{2}$, Eduardo Henrique Cronemberger ${ }^{3}$, Vinicius Carrera Souza ${ }^{4}$, Suelen Patricia dos Santos Martins ${ }^{5}$, Fábio Peixoto ${ }^{6}$, Oren Smaletz ${ }^{7}$, Fábio Schutz ${ }^{8}$, Daniel Herchenhorn ${ }^{9}$, Telma Santos ${ }^{10}$, Flavio Mavignier Carcano ${ }^{11}$, David Queiroz Muniz ${ }^{12}$, Paulo R. S. Nunes Filho ${ }^{1}$, Facundo Zaffaroni ${ }^{1}$, Carlos Barrios ${ }^{1}$ and André Fay ${ }^{13}$

\begin{abstract}
Background: Testosterone suppression is the standard treatment for advanced prostate cancer, and it is associated with side-effects that impair patients' quality of life, like sexual dysfunction, osteoporosis, weight gain, and increased cardiovascular risk. We hypothesized that abiraterone acetate with prednisone (AAP) and apalutamide, alone or in combination, can be an effective hormonal therapy also possibly decreasing castration-associated side effects.

Methods: Phase II, open-label, randomized, efficacy trial of abiraterone acetate plus prednisone (AAP) and Androgen Deprivation Therapy (ADT) versus apalutamide versus the combination of AAP (without ADT) and apalutamide. Key eligibility criteria are confirmed prostate adenocarcinoma; biochemical relapse after definitive treatment (PSA $\geq 4 \mathrm{ng} / \mathrm{ml}$ and doubling time less than 10 months, or PSA $\geq 20 \mathrm{ng} / \mathrm{ml}$ ); newly diagnosed locally advanced or metastatic prostate cancer; asymptomatic to moderately symptomatic regarding bone symptoms. Patients with other histology besides adenocarcinoma or previous use of hormonal therapy or chemotherapy were excluded.

Discussion: There is an urgent need to study and validate regimens such as new hormonal agents that may add benefit to castration with an acceptable safety profile. We aim to evaluate if apalutamide in monotherapy or in combination with AAP is an effective and safety hormonal treatment that can spare patients of androgen deprivation therapy.
\end{abstract}

Trial registration: This trial was registered in ClinicalTrials.gov on October 16, 2017, under Identifier: NCT02867020.

Keywords: Castration-sensitive prostate cancer, Hormonal therapy, Androgen deprivation therapy, Abiraterone, Apalutamide, Goserelin

\footnotetext{
* Correspondence: gustavo.werutsky@lacog.org.br

${ }^{1}$ Latin American Cooperative Oncology Group, Ipiranga Avenue 6681, 99A,

Room, Porto Alegre 806, Brazil

Full list of author information is available at the end of the article
}

(c) The Author(s). 2019 Open Access This article is distributed under the terms of the Creative Commons Attribution 4.0 International License (http://creativecommons.org/licenses/by/4.0/), which permits unrestricted use, distribution, and reproduction in any medium, provided you give appropriate credit to the original author(s) and the source, provide a link to the Creative Commons license, and indicate if changes were made. The Creative Commons Public Domain Dedication waiver (http://creativecommons.org/publicdomain/zero/1.0/) applies to the data made available in this article, unless otherwise stated. 


\section{Background}

Patients with advanced prostate cancer are generally treated with surgical or chemical castration. Despite high response rates with this strategy, testosterone suppression is associated with libido loss, sexual dysfunction, hot flushes, osteoporosis, muscle weakness and weight gain [1]. Moreover, patients with metastatic prostate cancer are living longer as a result of several new life-prolonging treatments with good symptomatic control, most notably when androgen deprivation therapy is initiated early for rising prostate-specific antigen (PSA) after the front-line treatment for the primary tumor. Therefore, there is a need to investigate if other hormonal therapies that can robustly suppress androgen signaling may spare the side-effects typically associated with conventional castration [2-4].

Abiraterone acetate, which inhibits the key enzyme cytochrome P450 c17 (CYP17), prevents androgen production by testes, adrenal gland and the prostate tumor [5]. In Phase III clinical trials, AAP showed improved efficacy against placebo in patients with metastatic castration-resistant prostate cancer, pre and post-chemotherapy, along with an acceptable safety profile [6-8]. Moreover, AAP together with androgen deprivation therapy improved survival in patients with newly diagnosed, metastatic, castration-sensitive prostate cancer in the LATITUDE [9] and STAMPEDE trials [10].

Apalutamide is a second-generation antiandrogen that emerged from a structure/activity relationshipguided medicinal chemistry program to design more potent antiandrogens with no significant agonistic activity in the setting of AR overexpression [11]. A Phase II trial including 21 patients with castrationresistant prostate cancer who had failed prior abiraterone treatment has shown a response rate of $24 \%$ [11]. Additionally, co-targeting the androgen receptor and paracrine androgen biosynthesis in castration-resistant prostate cancer may be more effective than either alone. A Phase II study evaluated the activity of AAP and enzalutamide, another second-generation antiandrogen, at the conventional doses in $60 \mathrm{pa}$ tients and reported a PSA decline $\geq 50 \%$ and $\geq 90 \%$ in 76 and $45 \%$ of patients, respectively, with an acceptable non-overlapping safety profile [12]. Additionally, another Phase II study [13] evaluated enzalutamide alone in hormone-naïve patients, without ADT, in 67 patients and shown a 92.5\% PSA response rate (a decline of $80 \%$ or greater), regardless of metastases at baseline.

There is limited evidence for clinical application of these second-generation hormonal agents either alone or in combination in metastatic prostate cancer with non-castrate testosterone levels. In the phase III SPARTAN trial [14], apalutamide in combination with androgen deprivation therapy prolonged metastasis-free survival in men with nonmetastatic castration-resistant prostate cancer; noteworthy, apalutamide did not increase androgen suppression side effects as compared with placebo. As a result, apalutamide was approved in the United States in this setting.

\section{Methods/design \\ Study design}

This is a phase II, open-label, randomized trial evaluating the efficacy of abiraterone acetate plus prednisone and Androgen Deprivation Therapy (ADT) versus apalutamide versus the combination of AAP (without ADT) and apalutamide, both at the standard doses, in patients with advanced or metastatic prostate cancer with non-castrate testosterone levels (Fig. 1). The total study period is 2 years including patient treatment and outcome data collection. Patients will be treated until objective or clinical disease progression or the occurrence of unacceptable toxicity. Patients are allowed to continue study treatment beyond the 25-week assessment (extension phase) at the discretion of the investigator. It will be conducted in 10 sites located in Brazil.

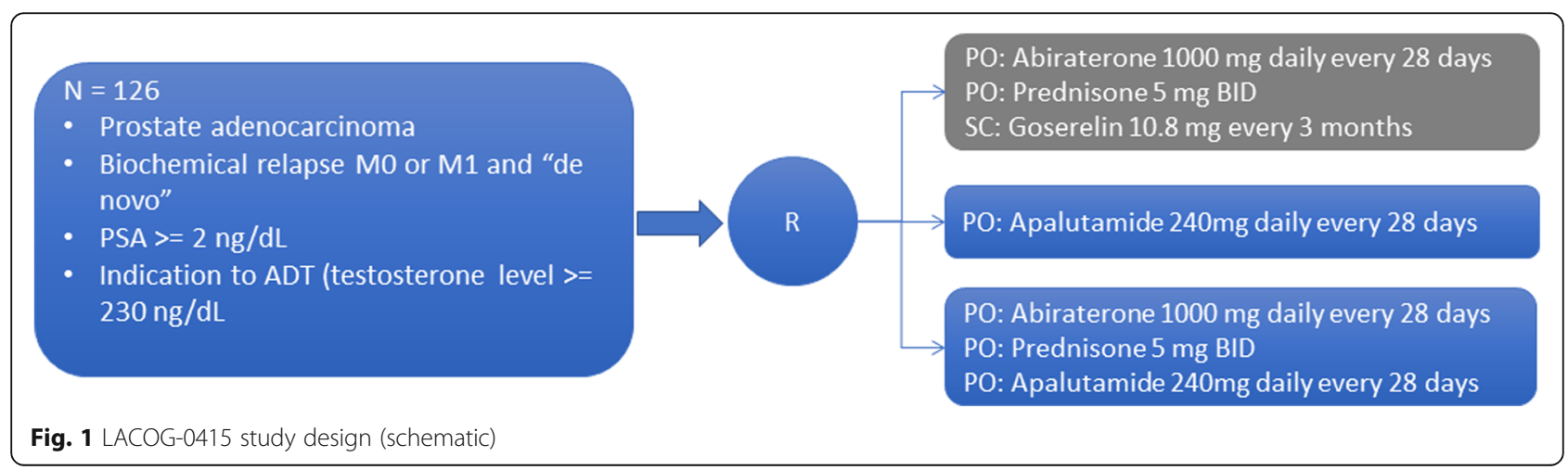




\section{Ethical considerations}

The study protocol was reviewed and approved by the Institutional Review Board of all participating institutions (see details in Appendix 1). Written informed consent will be obtained from all participants by investigators before any study procedure. This trial was registered in ClinicalTrials.gov trial registry (NCT02867020).

\section{Inclusion criteria}

Each potential subject must fulfill all of the following criteria to be enrolled in the study:

1. Histologically confirmed prostate adenocarcinoma;

2. Patients with indication to start treatment with ADT in one of the following settings:

a. Biochemical relapse after definitive front-line treatment (surgery and/or radiotherapy): PSA $\geq 4 \mathrm{ng} / \mathrm{ml}$ and doubling time less than 10 months, or PSA $\geq 20 \mathrm{ng} / \mathrm{ml}$;

b. Newly diagnosed Prostate Cancer: locally advanced - Tany N+ M0 (not a candidate to definitive treatment with surgery or radiotherapy) or metastatic - Tany Nany $\mathrm{M}+$ and PSA $\geq 2 \mathrm{ng} / \mathrm{mL}$;

3. The patient is asymptomatic to moderately symptomatic regarding bone symptoms, i.e., no need for palliative radiation or radionuclide therapy;

4. Complete staging process (performed as per routine), meaning, thorax, abdomen and pelvis TC and bone scan, performed before consent and that do not exceed 10 weeks prior to the date of randomization

5. Non-castration level of testosterone $\geq 230 \mathrm{ng} / \mathrm{dL}$ $(>8 \mathrm{nmol} / \mathrm{L})$;

6. ECOG performance status of 0 to 2;

7. Adequate hematologic, hepatic and renal function:

a. hemoglobin $>10 \mathrm{~g} / \mathrm{dL}$, neutrophils $>1.5 \times 10^{9} /$ $\mathrm{L}$, platelets $>100 \times 10^{9} / \mathrm{L}$;

b. total bilirubin $<1.5 \mathrm{x}$ upper limit of normal (ULN); alanine (ALT) and aspartate (AST) aminotransferase $<2.5 \times$ ULN;

c. serum creatinine $<1.5 \mathrm{x}$ ULN; potassium $>3.5 \mathrm{mM}$;

8. No previous cancer (except treated basal-cell skin cancer);

9. Written informed consent obtained prior to any study procedure;

10. Age 18 years and older;

11. Agrees to use a condom and another effective method of birth control if he is having sex with a woman of childbearing potential or agrees to use a condom if he is having sex with a woman who is pregnant

\section{Exclusion criteria}

Any potential subject who meets any of the following criteria will be excluded from participating in the study.

1. Prostate adenocarcinoma with neuroendocrine differentiation or small cell histology;

2. Use of hormonal therapy or chemotherapy prior to randomization. The exception is courses of hormone therapy for localized disease, that must have been completed at least 12 months previously. It could have been given as adjuvant or neoadjuvant therapy.

3. Prior radiation therapy for a primary tumor within the 3 months before enrollment or for the treatment of metastases;

4. Known or suspected brain or skull metastases or leptomeningeal metastatic disease;

5. Any concurrent severe and/or uncontrolled medical conditions which could compromise participation in the study;

6. Administration of an investigational therapeutic or invasive surgical procedure within 28 days of Cycle 1 Day 1 or currently enrolled in an investigational study;

7. Active or symptomatic viral hepatitis or chronic liver disease; ascites or bleeding disorders secondary to hepatic dysfunction;

8. Current or prior treatment with anti-epileptic medications for the treatment of seizures;

9. Impaired cardiac function, including any of the following:

a. Uncontrolled hypertension (systolic blood pressure $\geq 160 \mathrm{mmHg}$ or diastolic $\mathrm{BP} \geq 95 \mathrm{mmHg}$ );

b. Clinically significant heart disease as evidenced by myocardial infarction, or arterial thrombotic events or history of cardiac failure in the past 6 months, severe or unstable angina, or New York Heart Association (NYHA) Class II-IV heart disease;

c. Existing atrial fibrillation with or without pharmacotherapy. Other cardiac arrhythmia requiring pharmacotherapy;

10. History of seizure or condition that may predispose to seizure (including, but not limited to prior stroke, transient ischemic attack or loss of consciousness $\leq 1$ year prior to randomization; brain arteriovenous malformation; or intracranial masses such as schwannomas and meningiomas that are causing edema or mass effect);

11. Specific underlying conditions for oral agents. For example impairment of gastrointestinal (GI) function or GI disease that may significantly alter the absorption of abiraterone acetate or apalutamide (e.g., ulcerative diseases, uncontrolled 
nausea, vomiting, diarrhea, malabsorption syndrome, or small bowel resection)

12. General excluded medications (e.g., relevant to cytochrome P450 interactions)

a. Use of prescription drugs within 14 days prior to dosing or over-the-counter (OTC) medication within 7 days prior to dosing;

b. Consumption of grapefruit product or St John's wort within 7 days prior to dosing;

c. G-CSF, GM-CSF, erythropoietin, etc.;

d. Coumadin;

e. Drugs which may cause QT prolongation;

f. Known sensitivity to drugs or metabolites from similar classes;

g. Known or suspected contraindications or hypersensitivity to apalutamide, bicalutamide or $\mathrm{GnRH}$ agonists or any of the components of the formulations;

13. Any condition or situation which, in the opinion of the investigator, would put the subject at risk, may confound study results, or interfere with the subject's participation in this study;

14. Surgical castration prior to study entry.

\section{Allocation and study treatment}

Patients will be randomly assigned to three arms in a 1:1:1 ratio. The randomization will be balanced by using randomly permuted blocks. Randomization will take place across all study sites using a centralized Interactive Web Response System (IWRS). Subjects will be stratified by performance status (ECOG $0-1$ vs 2 ) and metastatic disease (yes vs. no).

The study arms will be consisted of:

- Arm 1 (CONTROL): Abiraterone acetate + Prednisone + ADT (Goserelin).

- Abiraterone acetate administered at a single 1000 mg daily oral dose $(4 \times 250 \mathrm{mg}$ tablets $)$

- Prednisone administered at a $5 \mathrm{mg}$ twice daily oral dose

- Goserelin administered as subcutaneous injections of $10.8 \mathrm{mg}$ every 3 months

- Arm 2: Apalutamide monotherapy

- Apalutamide administered at a single $240 \mathrm{mg}$ daily oral dose $(4 \times 60 \mathrm{mg}$ tablets)

- Arm 3: Abiraterone acetate + Prednisone + Apalutamide

- Abiraterone acetate administered at a single 1000 mg daily oral dose $(4 \times 250 \mathrm{mg}$ tablets $)$

- Prednisone administered at a $5 \mathrm{mg}$ twice daily oral dose

- Apalutamide administered at a single $240 \mathrm{mg}$ daily oral dose $(4 \times 60 \mathrm{mg}$ tablets)
Per protocol, study treatment is planned until week-25. Patients will be treated until objective or clinical disease progression or the occurrence of unacceptable toxicity. Patients are allowed to continue study treatment beyond week 25 (extension phase) at the discretion of the investigator.

Patients will be discontinued from the planned study treatment due to progression (radiographic per RECIST 1.1 and/or symptomatic +/- biochemical according to PCWG3 criteria), adverse event or patient withdrawal.

\section{Study outcomes and procedures}

The primary endpoint of this study is to evaluate the proportion of patients who achieve an undetectable PSA level, defined as $\leq 0.2 \mathrm{ng} / \mathrm{mL}$, at week 25 in each of three arms. Secondary endpoints are: determine and compare PSA progression rate at week 25 (PCWG3 criteria); determine and compare PSA response of 50 and $80 \%$ at week 25; determine maximum PSA declines and overall PSA change from baseline up to week 25 and up to week 52; determine the radiographic progression-free survival (rPFS) at week 25 among the three arms; determine and compare hormonal levels during treatment; determine and compare the safety profile; determine and compare the time to pain progression assessed by BPI-SF and opioid use; determine and compare the quality of life assessed by FACT-P; determine time to prostate cancer castration resistance; and metastasis-free survival (on non-metastatic patients at inclusion).

Table 1 shows the procedures which subjects will perform during all study phases. During the screening period, after signing informed consent, patients will undergo comprehensive clinical assessment, associated with cardiac evaluation (12 lead ECG and echocardiogram or MUGA). Following randomization, visits will be scheduled before each 28-day cycle, with evaluation of patient-reported outcomes, hematological and metabolic panel and PSA and testosterone levels. CT scans will be performed after 25 weeks, with a PSA confirmation at week 28. Afterward, patients who are benefiting from the study treatment, regardless of the treatment arm they have been assigned to, at week 25 are allowed to continue receiving this medication in an extension phase. These patients will be followed at 2 different times: 12 and 24 months after study treatment initiation. Biochemical and radiological progression and survival status data will be collected from the medical chart.

\section{Translational research}

This study intends to collect biological materials (FFPE blocks or slides and blood samples) from patients and 
Table 1 SPIRIT flow diagram of LACOG 0415 phase II trial

\begin{tabular}{|c|c|c|c|c|c|c|c|c|c|c|c|c|}
\hline \multicolumn{12}{|l|}{ Randomized study phase } & \multirow{2}{*}{$\begin{array}{l}\text { Extension study phase } \\
\text { Patient chart data } \\
\text { collection }\end{array}$} \\
\hline Cycle number & Screening & $\mathrm{C} 1$ & $\mathrm{C} 2$ & C3 & C4 & C5 & C6 & C7 & PSA Confirmation & $\begin{array}{l}\text { Safety } \\
\text { visit }\end{array}$ & $\begin{array}{l}\text { Patient chart data } \\
\text { collection }\end{array}$ & \\
\hline Week & & 0 & 4 & 8 & 12 & 16 & 20 & 25 & 28 & & Year 1 & Year 2 \\
\hline \multicolumn{13}{|l|}{ Enrolment } \\
\hline Eligibility screen & $x$ & & & & & & & & & & & \\
\hline Informed consent & $x$ & & & & & & & & & & & \\
\hline $\begin{array}{l}\text { Medical history/clinical } \\
\text { evaluation/vital signs/ } \\
\text { physical examination/ } \\
\text { ECOG/concomitant } \\
\text { medication assessment }\end{array}$ & $x$ & $x$ & $x$ & $x$ & $x$ & $x$ & $x$ & $x$ & & $x$ & & \\
\hline $\begin{array}{l}12 \text { lead ECG/Echocardiogram } \\
\text { or MUGA }\end{array}$ & $x$ & & & & & & & $x$ & & & & \\
\hline \multicolumn{13}{|l|}{ Interventions } \\
\hline $\begin{array}{l}\text { Arm 1: Abiraterone + } \\
\text { prednisona + Goserelin }\end{array}$ & & $x$ & $x$ & $x$ & $x$ & $x$ & $x$ & & & & & \\
\hline $\begin{array}{l}\text { Arm 2: Apalutamide } \\
\text { monotherapy }\end{array}$ & & $x$ & $x$ & $x$ & $x$ & $x$ & $x$ & & & & & \\
\hline $\begin{array}{l}\text { Arm 3: Abiraterona + } \\
\text { Prednisone + Apalutamide }\end{array}$ & & $x$ & $x$ & $x$ & $x$ & $x$ & $x$ & & & & & \\
\hline Study drug accountability & & $x$ & $x$ & $x$ & $x$ & $x$ & $x$ & $x$ & & & & \\
\hline \multicolumn{13}{|l|}{ Assessments } \\
\hline CT scans & & & & & & & & $x$ & & & & \\
\hline Bone scan & & & & & & & & & & & $x$ & \\
\hline Hematology & $x$ & & & $x$ & & $x$ & & $x$ & & $x$ & & \\
\hline Biochemistry & $x$ & & $x$ & $x$ & $x$ & $x$ & $x$ & $x$ & & $x$ & & \\
\hline PSA & $x$ & & $x$ & $x$ & $x$ & $x$ & $x$ & $x$ & $x$ & & & \\
\hline Testoterone levels & $x$ & & $x$ & $x$ & $x$ & $x$ & $x$ & $x$ & $x$ & & & \\
\hline $\begin{array}{l}\text { Patient reported } \\
\text { outcomes (PRO) }\end{array}$ & & $x$ & $x$ & $x$ & $x$ & $x$ & $x$ & $x$ & & & & \\
\hline Survival Status & & & & & & & & & & & $x$ & $x$ \\
\hline
\end{tabular}

create a biorepository for translational research projects. The biorepository will comply with the current regulations in Brazil. Biomarker studies on the FFPE blocks or slides of tumor samples may include immunohistochemistry analyses, global miRNA profiling, tumor gene-expression profiling, and somatic mutational analyses.

Data collected from this study will be compared to historical data obtained from prior studies in advanced/metastatic hormone-sensitive prostate cancer to identify miRNA and GEP that correlate with the response (or primary resistance) to AAP and apalutamide. The biomarker results from this study will then be used to inform future studies of anti-androgen therapies possibly leading to product differentiation by selection of responsive subjects. Furthermore, we plan to investigate whether miRNA profiles may better define high-risk prostate cancer in the early advanced/ metastatic disease setting. This data may then be utilized in the selection of high-risk patients in future studies if these previously reported miRNA profiles are confirmed and found to be more sensitive than conventional clinical estimates of high-risk disease.

\section{Statistical analysis}

All statistical analyses specified in this protocol will be conducted using SAS version 9.4 and a significance level of $5 \%$. For the primary endpoint (PSA below $0.2 \mathrm{ng} / \mathrm{mL}$ at week 25), and using Fleming one-stage method, a sample size of 38 participants per arm would allow $80 \%$ power to reject a PSA undetectable rate (defined as $\leq 0.2$ $\mathrm{ng} / \mathrm{mL}$ ) of $45 \%$ or less, with an expected PSA response rate for each of the three arms of about $65 \%[15,16]$. All the efficacy analyses will take place using the intention to treat (ITT) population. No interim analysis for futility is planned. 
Demographics and baseline disease characteristics will be analyzed using descriptive statistics. There is no formal statistical analysis plan for health-related quality of life (HRQOL). The FACT-P data will be scored and handled as recommended in its respective User's manual [17]. Scores for each patient will be measured at baseline and every four weeks until week 25 and will be presented a spider-plot, without comparison between treatment arms. Differences greater than 10-points will be considered clinically significant [18]. The time-to-event endpoint will be estimated by Kaplan-Meier method and compared by stratified log-rank test or Cox regression method. Dichotomic data will be analyzed using Ficher's exact test or Chi-squared test. If necessary, other methods for categorical data may also be applied as appropriate.

\section{Discussion}

Management of locally advanced or metastatic prostate cancer still remains a clinical challenge. Androgen deprivation therapy remains the current standard of care, with high response rates in treatment-naïve patients, although most patients progress to castration-resistant prostate cancer [19]. Aside from its clinical efficacy, ADT is associated with adverse events that affect patients quality of life, as libido loss, sexual dysfunction, hot flushes, osteoporosis, muscle weakness and weight gain $[1,2]$. Consequently, there is an unmet medical need for active treatments against the disease that can spare patients of testosterone suppression.

Apalutamide is a second-generation antiandrogen with a potent affinity for the AR but, unlike first-generation drugs, has no significant risk of agonistic activity [11]. In a phase II trial including 51 patients with non-metastatic castration-resistant prostate cancer, $89 \%$ patients had a biochemical response with a median time to PSA progression of 24 months, showing a robust activity with a tolerable safety profile [20]. Another phase II trial including 21 patients with castration-resistant prostate cancer who had failed prior abiraterone treatment has shown a response rate of $24 \%$ [21]. These data support the use of apalutamide monotherapy as an interesting option for patients with advanced/metastatic castration-sensitive prostate cancer. Additionally, as seen in the phase III SPARTAN trial [14], in men with nonmetastatic CRPC, apalutamide and ADT prolonged metastasis-free survival from 16.2 to 40.5 months (hazard ratio for metastasis or death, 0.28 ; $95 \%$ confidence interval, 0.23 to $0.35 ; P<0.001)$. The more frequent adverse events as compared with placebo were rash, hypothyroidism, and fracture. There was no difference in androgen suppression-related side effects.
Abiraterone acetate is a selective inhibitor of androgen biosynthesis. It is currently approved in many countries in combination with prednisone, including Brazil and USA, for patients with metastatic castration-resistant prostate cancer based on two large randomized phase 3 clinical trials demonstrating a survival benefit for patients regardless of prior exposure to chemotherapy in metastatic setting [6-8]. Additionally, the recently published LATITUDE [9] and STAMPEDE [10] trials shown that the combination of AAP with ADT in patients with high risk metastatic castration-sensitive disease improves overall survival, leading to a use of this combination as a control arm in the present study. Moreover, abiraterone acetate plus apalutamide combination was evaluated in a phase IB [22] trial in 57 patients with progressive metastatic CRPC and shown a $67 \%$ PSA decline rate $(\geq 50 \%)$ for patients who were abiraterone and enzalutamide-naïve. Conversely, in patients who were previously treated with those drugs, the rate was only $15 \%$. Currently, there are two phase 3 trials active evaluating the combination for patients with metastatic (NCT02257736) or high-risk biochemically relapsed (NCT03009981) disease. Therefore, we hypothesized that the combination of AAP with apalutamide can at least provides the same benefit of the combination of AAP with ADT also possibly decreasing castration-associated side effects.

On the other hand, although two randomized trials have shown a survival benefit of adding docetaxel to androgen suppression in hormone naïve prostate cancer [23, 24], especially in patients with high volume disease, toxicity in both trials was higher in the chemotherapy/ hormonal arms despite the survival benefit. Therefore, due to age and/or comorbidities when patients are not suitable candidates for chemotherapy, there is an urgent need to study and validate regimens such as new hormonal agents that may add benefit to castration with an acceptable safety profile.

One important limitation to consider in our study is that we chose the proportion of patients with PSA levels less than $0.2 \mathrm{ng} / \mathrm{mL}$ as our main endpoint because it is deemed a valid marker of prostate cancer treatment response. However, hormonal manipulation may change PSA levels without any significant difference in survival. Therefore, a phase 3 trial will be necessary even if our study is considered positive.

We expect that this study can answer the question if apalutamide as monotherapy or in combination with AAP is an effective hormonal treatment for patients with castration-sensitive advanced or metastatic prostate cancer, with acceptable safety profile, and possibly spare patients of androgen deprivation therapy side effects, as sexual dysfunction, osteoporosis, hot flushes, weight gain and increased cardiovascular risk. 


\section{Appendix}

Table 2 Details of all Ethics Committees which approved LACOG 0415 Protocol

\begin{tabular}{|c|c|c|c|}
\hline INSTITUTION & ETHICS COMMITTEE & CITY & DATE OF APPROVAL \\
\hline Hospital São José & $\begin{array}{l}\text { HOSPITAL BENEFICÊNCIA } \\
\text { PORTUGUESA DE SÃO PAULO }\end{array}$ & São Paulo & 9/9/2016 \\
\hline Clínica AMO & FUNDAÇÃO BAHIANA DE CARDIOLOGIA - FBC & Salvador & $6 / 20 / 2017$ \\
\hline CEPHO & $\begin{array}{l}\text { FACULDADE DE MEDICINA DO } \\
\text { ABCIFUNDAÇÃO DO ABC - } \\
\text { FMABC }\end{array}$ & Santo André & $5 / 17 / 2017$ \\
\hline CPO-RS & $\begin{array}{l}\text { PONTIFÍCIA UNIVERSIDADE } \\
\text { CATÓLICA DO RIO GRANDE } \\
\text { DO SUL - PUC/RS }\end{array}$ & Porto Alegre & $5 / 25 / 2017$ \\
\hline CRIO & $\begin{array}{l}\text { UFC - UNIVERSIDADE } \\
\text { FEDERAL DO CEARÁ }\end{array}$ & Fortaleza & $2 / 14 / 2017$ \\
\hline Hospital do Câncer de Barretos & $\begin{array}{l}\text { HOSPITAL DO CÂNCER DE } \\
\text { BARRETOS / FUNDAÇÃO PIO } \\
\text { XII }\end{array}$ & Barretos & $1 / 26 / 2017$ \\
\hline Oncologia D’Or & $\begin{array}{l}\text { HOSPITAL PRÓ-CARDÍACO - } \\
\text { ESHO EMPRESA DE } \\
\text { SERVIÇOS HOSPITALARES }\end{array}$ & Rio de Janeiro & $4 / 6 / 2017$ \\
\hline $\mathrm{COI}$ & $\begin{array}{l}\text { HOSPITAL PRÓ-CARDÍACO - } \\
\text { ESHO EMPRESA DE } \\
\text { SERVIÇOS HOSPITALARES }\end{array}$ & Rio de Janeiro & $3 / 5 / 2017$ \\
\hline ICESP & $\begin{array}{l}\text { USP - FACULDADE DE } \\
\text { MEDICINA DA UNIVERSIDADE } \\
\text { DE SÃO PAULO - FMUSP }\end{array}$ & São Paulo & $4 / 5 / 2017$ \\
\hline Einstein & $\begin{array}{l}\text { HOSPITAL ISRAELITA ALBERT } \\
\text { EINSTEIN-SP }\end{array}$ & São Paulo & $6 / 26 / 2017$ \\
\hline Liga NG & $\begin{array}{l}\text { LIGA NORTE RIOGRANDENSE } \\
\text { CONTRA O CÂNCER }\end{array}$ & Natal & 9/4/2018 \\
\hline Hospital Caridade ljuí & $\begin{array}{l}\text { UNIVERSIDADE REGIONAL DO } \\
\text { NOROESTE DO ESTADO DO } \\
\text { RIO GRANDE DO SUL - UNIJUII }\end{array}$ & ljuí & $10 / 8 / 2018$ \\
\hline Hospital Erasto Gaertner & $\begin{array}{l}\text { HOSPITAL ERASTO } \\
\text { GAERTNER - LIGA } \\
\text { PARANAENSE DE COMBATE }\end{array}$ & Curitiba & $9 / 12 / 2018$ \\
\hline IBCC & $\begin{array}{l}\text { INSTITUTO BRASILEIRO DE } \\
\text { CONTROLE DO CÂNCER - } \\
\text { IBCC/ ONCOLOGIA CLÍNICA }\end{array}$ & São Paulo & $9 / 11 / 2018$ \\
\hline
\end{tabular}

\section{Abbreviations}

ADT: Androgen deprivation therapy; AR: Androgen receptor; FFPE: Formalinfixed paraffin-embedded; GEP: Gene-expression profile; ITT: Intention to treat; miRNA: micro-ribonucleic acid

\section{Acknowledgments}

We would like to acknowledge SAS Institute Inc. for providing a free of charge license for academic use.

\section{Funding}

The Latin American Cooperative Oncology Group (LACOG) is the legal sponsor of this study. This study is an investigator initiated research funded by Janssen-Cilag Farmacêutica Ltda, which provided financial support and drug supply. LACOG is responsible for the study design, data collection and analysis, interpretation of the results and manuscript writing.

\section{Availability of data and materials}

Data sharing is not applicable to this article as no datasets were generated or analyzed during the current study.

\section{Authors' contributions}

GW, FCM, VCS, OS, FS, DH, TS, CB, and AF designed the study, FCM, EHC, VCS, SPSM, FP, OS, FS, DH, FMC, DQM and AF are study principal investigators; GW, FCM, PRSNF and FZ wrote the manuscript; all authors have read and approved the final manuscript.

Ethics approval and consent to participate

This study is currently on-going in 11 sites in Brazil, all of which had study documents (final protocol, any amendments, the informed consent form, applicable recruiting materials, and subject compensation programs) approved by Institutional Ethics Committee. All study participants provided written informed consent before any study procedure.

\section{Consent for publication}

Not applicable.

\section{Competing interests}

This study has received funding from a commercial organization. Otherwise, the authors declare that they have no competing interests. 


\section{Publisher's Note}

Springer Nature remains neutral with regard to jurisdictional claims in published maps and institutional affiliations.

\section{Author details}

'Latin American Cooperative Oncology Group, Ipiranga Avenue 6681, 99A, Room, Porto Alegre 806, Brazil. ${ }^{2}$ Hospital São José, São Paulo, Brazil. ${ }^{3}$ Centro Regional Integrado de Oncologia, Fortaleza, Brazil. ${ }^{4}$ Clínica Assistência Multidisciplinar em Oncologia, Salvador, Brazil. ${ }^{5}$ Centro de Estudos e Pesquisa de Hematologia e Oncologia, Santo André, Brazil. ${ }^{6}$ Americas Centro de Oncologia Integrado, Rio de Janeiro, Brazil. ${ }^{7}$ Hospital Israelita Albert Einstein São Paulo, Brazil. ${ }^{8}$ Beneficiência Portuguesa de São Paulo, São Paulo, Brazil. ${ }^{9}$ Oncologia D'Or, Rio de Janeiro, Brazil. ${ }^{10}$ Janssen Cilag Pharmaceutical, São Paulo, Brazil. ${ }^{11}$ Hospital do Câncer de Barretos, Barretos, Brazil. ${ }^{12}$ Instituto do Câncer do Estado de São Paulo, São Paulo, Brazil. ${ }^{13}$ PUCRS School of Medicine, Porto Alegre, Brazil.

Received: 5 May 2018 Accepted: 14 May 2019

Published online: 23 May 2019

\section{References}

1. Hershman DL, Unger JM, Wright JD, Ramsey S, Till C, Tangen CM, et al. Adverse health events following intermittent and continuous androgen deprivation in patients with metastatic prostate Cancer. JAMA Oncol. 2016; 2:453-61.

2. Rozet F, Roumeguère $T$, Spahn M, Beyersdorff D, Hammerer P. Nonmetastatic castrate-resistant prostate cancer: a call for improved guidance on clinical management. World J Urol. 2016;34:1505-13.

3. Crawford ED, Higano CS, Shore ND, Hussain M, Petrylak DP. Treating patients with metastatic castration resistant prostate Cancer: a comprehensive review of available therapies. J Urol. 2015;194:1537-47.

4. Gartrell BA, Coleman R, Efstathiou E, Fizazi K, Logothetis CJ, Smith MR, et al. Metastatic prostate Cancer and the bone: significance and therapeutic options. Eur Urol. 2015;68:850-8.

5. Barrie SE, Potter GA, Goddard PM, Haynes BP, Dowsett M, Jarman M Pharmacology of novel steroidal inhibitors of cytochrome P450(17) alpha (17 alpha-hydroxylase/C17-20 lyase). J Steroid Biochem Mol Biol. 1994;50:267-73.

6. de Bono JS, Logothetis CJ, Molina A, Fizazi K, North S, Chu L, et al. Abiraterone and increased survival in metastatic prostate cancer. N Engl J Med. 2011;364:1995-2005.

7. Fizazi K, Scher HI, Molina A, Logothetis CJ, Chi KN, Jones RJ, et al. Abiraterone acetate for treatment of metastatic castration-resistant prostate cancer: final overall survival analysis of the COU-AA-301 randomised, double-blind, placebocontrolled phase 3 study. Lancet Oncol. 2012;13:983-92.

8. Ryan CJ, Smith MR, de Bono JS, Molina A, Logothetis CJ, de Souza P, et al. Abiraterone in metastatic prostate Cancer without previous chemotherapy. N Engl J Med. 2013;368:138-48.

9. Fizazi K, Tran N, Fein L, Matsubara N, Rodriguez-Antolin A, Alekseev BY, et al. Abiraterone plus prednisone in metastatic, castration-sensitive prostate Cancer. N Engl J Med. 2017:377:352-60.

10. James ND, de Bono JS, Spears MR, Clarke NW, Mason MD, Dearnaley DP, et al. Abiraterone for prostate Cancer not previously treated with hormone therapy. N Engl J med 2017; 377: 338-351.11. Rathkopf DE, Morris MJ, fox JJ, Danila DC, Slovin SF, Hager JH, et al. phase I study of ARN-509, a novel antiandrogen, in the treatment of castration-resistant prostate cancer. J Clin Oncol Off J Am Soc Clin Oncol. 2013;31:3525-30.

11. Rathkopf DE, Smith MR, Ryan CJ, Berry WR, Shore ND, Liu G, et al. Androgen receptor mutations in patients with castration-resistant prostate cancer treated with apalutamide. Ann Oncol Off J Eur Soc Med Oncol. 2017;28:2264-71.

12. Efstathiou E, Titus MA, Wen S, SanMiguel A, Hoang A, De Haas-Amatsaleh A, et al. Enzalutamide (ENZA) in combination with abiraterone acetate (AA) in bone metastatic castration resistant prostate cancer (mCRPC). J Clin Oncol. 2014;32(15_suppl):5000.

13. Tombal B, Borre M, Rathenborg P, Werbrouck $P$, Van Poppel $H$, Heidenreich $A$, et al. Enzalutamide monotherapy in hormone-naive prostate cancer: primary analysis of an open-label, single-arm, phase 2 study. Lancet Oncol. 2014:15:592-600.

14. Smith MR, Saad F, Chowdhury S, Oudard S, Hadaschik BA, Graff JN, et al. Apalutamide treatment and metastasis-free survival in prostate Cancer. $\mathrm{N}$ Engl J Med. 2018;378:1408-18.
15. Hussain M, Tangen CM, Higano C, Schelhammer PF, Faulkner J, Crawford ED, et al. Absolute prostate-specific antigen value after androgen deprivation is a strong independent predictor of survival in new metastatic prostate cancer: data from southwest oncology group trial 9346 (INT-0162). J Clin Oncol Off J Am Soc Clin Oncol. 2006;24:3984-90.

16. Chang D, Joseph DJ, Ebert MA, Galvão DA, Taaffe DR, Denham JW, et al. Effect of androgen deprivation therapy on muscle attenuation in men with prostate cancer. J Med Imaging Radiat Oncol. 2014;58:223-8.

17. Esper P, Mo F, Chodak G, Sinner M, Cella D, Pienta KJ. Measuring quality of life in men with prostate cancer using the functional assessment of cancer therapy-prostate instrument. Urology. 1997 Dec;50(6):920-8.

18. Cella D, Nichol MB, Eton D, Nelson JB, Mulani P. Estimating clinically meaningful changes for the functional assessment of Cancer therapy-prostate: results from a clinical trial of patients with metastatic hormonerefractory prostate cancer. Value Health. 2009 Feb;12(1):124-9.

19. Chi KN, Bjartell A, Dearnaley D, Saad F, Schröder FH, Sternberg C, et al. Castration-resistant prostate cancer: from new pathophysiology to new treatment targets. Eur Urol. 2009;56:594-605.

20. Smith MR, Antonarakis ES, Ryan CJ, Berry WR, Shore ND, Liu G, et al. Phase 2 study of the safety and antitumor activity of Apalutamide (ARN-509), a potent androgen receptor antagonist, in the high-risk nonmetastatic castration-resistant prostate Cancer cohort. Eur Urol. 2016:70:963-70.

21. Rathkopf DE, Antonarakis ES, Shore ND, Tutrone R, Alumkal JJ, Ryan CJ, et al. ARN-509 in men with metastatic castration-resistant prostate cancer (mCRPC). J Clin Oncol. 2013;31(6_suppl):48.

22. Posadas EM, Chi KN, De Wit R, De Jonge MJ, Attard G, Friedlander TW, et al. Phase Ib study of apalutamide (APA) with abiraterone acetate (AA) and prednisone $(\mathrm{P})$ in patients (pts) with metastatic castration-resistant prostate cancer (mCRPC): update on safety and efficacy. J Clin Oncol. 2017 Feb 20; 35(6_suppl):173.

23. Sweeney CJ, Chen Y-H, Carducci M, Liu G, Jarrard DF, Eisenberger M, et al. Chemohormonal therapy in metastatic hormone-sensitive prostate Cancer. N Engl J Med. 2015;373:737-46.

24. James ND, Sydes MR, Clarke NW, Mason MD, Dearnaley DP, Spears MR, et al. Addition of docetaxel, zoledronic acid, or both to first-line long-term hormone therapy in prostate cancer (STAMPEDE): survival results from an adaptive, multiarm, multistage, platform randomised controlled trial. Lancet. 2016:387:1163-77

\section{Ready to submit your research? Choose BMC and benefit from:}

- fast, convenient online submission

- thorough peer review by experienced researchers in your field

- rapid publication on acceptance

- support for research data, including large and complex data types

- gold Open Access which fosters wider collaboration and increased citations

- maximum visibility for your research: over $100 \mathrm{M}$ website views per year

At $\mathrm{BMC}$, research is always in progress.

Learn more biomedcentral.com/submissions 